\title{
Phytobeneficial Traits and Ecophysiological Stress Tolerance of Rhizobia
}

\author{
Reshid Abafita Abawari \\ Jimma agricultural research center, Natural resource management process, \\ Addis Ababa University, Ethiopia
}

This journal is licensed under a Creative Commons Attribution-NonCommercial 4.0 International License (CC-BY-NC). Articles can be read and shared for noncommercial purposes under the following conditions:

- BY: Attribution must be given to the original source (Attribution)

- NC: Works may not be used for commercial purposes (Noncommercial)

This license lets others remix, tweak, and build upon your work non-commercially, and although their new works must also acknowledge you and be non-commercial, they don't have to license their derivative works on the same terms. License Deed Link: http://creativecommons.org/licenses/by-nc/4.0/

Legal Code Link: http://creativecommons.org/licenses/by-nc/4.0/legalcode

$A B C$ Research Alert uses the CC BY-NC to protect the author's work from misuse.

\section{Abstract}

The microorganisms with the aim of improving nutrients available for plants are an important practice and necessary for agriculture. During the past couple of decades, plant growth-promoting (PGP) rhizobia have been begun to replace the use of chemicals in agriculture, horticulture and environmental cleanup strategies. Scientific researches involve multidisciplinary approaches to understand adaptation of plant growth promoting rhizobacteria (PGPR), their effects on plant physiology and growth, induced systemic resistance, biocontrol of plant pathogens, biofertilization and their tolerance to ecophysiological stresses. This is due to the emerging demand for dependence diminishing of synthetic chemical products, to the growing necessity of sustainable agriculture within a holistic vision of development and to focus on environmental protection. PGP rhizobia are naturally occurring soil bacteria that aggressively colonize plant roots and benefit plants by providing growth promotion and biological nitrogen fixation (BNF). Inoculation of crop plants with certain strains of PGP rhizobia at an early stage of development improves biomass production and yields through direct and indirect effects on roots and shoots growth. In this review, we have discussed the phytobeneficial traits of rhizobia which act as PGPR, and their ecophysiological properties, biocontrolability, mechanisms and the desirable properties exhibited by them.

\section{Keywords}

Phytobeneficial traits, Ecophysiology, nitrogen fixation, Phosphate solubilization, siderophore production, rhizosphere.

\section{INTRODUCTION}

The rhizosphere is a nutrient-rich habitat and harbors a huge variety of bacteria and fungi that each can have neutral, beneficial or harmful effects on the plant (Berendsen et al., 2012). Adesemoye and Kloepper (2009) indicated plant growth and yield stimulation by beneficial soil microorganisms and plant growth promoting rhizobacteria (PGPR) is one among the most effective and best studied soil microorganisms which can promote plant performance. Plants inturn help beneficial soil microbes by giving an auxiliary environment in the rhizosphere and microbes in return also provide several benefits to plants such as growth promotion and stress relief. Hence plant roots ooze different organic nutrients such as sugar, vitamins, organic acids, amino acids, mucilage, phytosiderophores, nucleosides, phenolic compounds and 
other signals. This results in enrichment of microorganisms, such as bacteria, fungus, algae and protozoa, among which bacteria influence the plant growth in a most significant manner (Uren 2007).

Plant growth promoting rhizobacteria (PGPR) found in the rhizosphere in association with roots (Glick, 2012) are beneficial bacteria which can heighten the growth of plants either directly by nitrogen fixation, phosphate solubilization, iron chelation and phytohormone production or indirectly by suppression of plant pathogenic organisms, induction of resistance in host plants against plant pathogens and abiotic stresses (Vessey,2003).

Rhizobium is one of the plant growths promoting rhizobacteria (PGPR) which exhibit a variety of characteristics responsible for influencing plant growth and performance. As a symbiotic partner in addition to nitrogen supply, rhizobium also improves nutritional uptake by promoting the growth of plant root system through production of indole acetic acid (IAA) (Etesami, et al.2009) and as a rhizospheric microbe solubilises phosphorus and various mineral nutrients (Khan, et al, 2006).

Plant growth could be induced by rhizobia through some of their growth stimulating mechanisms such as mobilization of nutrient, enhancement in stress resistance, solubilization of phosphates, production of phytohormones and siderophores (Ahmad, et al.2006).

The plant growth promoting (PGP) rhizobia olso serve as biocontrol agents. The ability of bacterial siderophores and antibiotics to suppress phytopathogens could be the significant agronomic importance. Both mechanisms have essential functions in microbial antagonism but also the mechanisms leads to bring out induced resistance. Resistance-inducing and antagonistic rhizobacteria might be useful in formulating new inoculants, offering an attractive alternate of environmentally friendly biological control of plant disease and improving the cropping systems into which it can be most profitably applied (Beneduzi et al., 2012).

Plant growth promoting (PGP) rhizobia contains a useful variation for tolerating environmental stresses like extremes of temperature, $\mathrm{pH}$, salinity and drought; heavy metals, antibiotics and pesticide pollution. Seeking such tolerant PGP rhizobia is expected to offer enhanced plant growth and yield even under a combination of stresses. The multiplicity of beneficial effects of rhizobial inoculants emphasize the need for further strengthening the research and their use in modern agriculture.Therefore genetic modification may accelerate the commercialization of PGP rhizobia as biocontrol agents that could further contribute to sustainable development of agriculture.

In this review we emphasized on the plant Growth-Promoting (PGP) traits of rhizobial related researchs and benefits of PGP rhizobia as well as their environmental stress tolerance. Moreover, the potential of PGP rhizobia and the unique properties of plant growth induction, defense pathways and the resistance spectrum available against various abiotic stresses on a variety of agricultural crops was summarized.

\section{PHYTOBENEFICIAL TRAITS OF RHIZOBIA}

Rhizobia, in addition to nitrogen supply, promote growth of the plants as a symbiotic partner and soil microbes in a number of ways. Plant growth could be induced by rhizobia through some of their growth stimulating mechanisms such as mobilization of nutrient, enhancement in stress resistance, solubilization of phosphates, production of phytohormones and siderophores (Ahmad et al., 2008). Generally, rhizobia can promote plant growth directly by either often due to their ability for nutrient supply (nitrogen, phosphorus, potassium and essential minerals) or modulating plant hormone levels, or indirectly by decreasing the inhibitory effects of various pathogens and ecophysiological Stress on plant growth and development in the forms of biocontrol agents, root colonizers and serve as environmental protectors (Kloepper and Schroth, 1981; Vessey, 2003).

\subsection{Nitrogen Fixation}

Biological Nitrogen fixation (BNF) is one of the most important biological processes on this planet and continued improvement in the understanding of the legume-rhizobia interaction is necessary to sustain a food supply to its inhabitants. Although $78 \%$ of the atmospheric air is $\mathrm{N}$ and it is required for synthesis of nucleic acids, enzymes, proteins and chlorophyll, this gaseous form is unavailable for direct assimilation by plants. 
Rhizobia are bacterial symbionts of legumes that fix and convert atmospheric nitrogen in a process known as biological nitrogen fixation (BNF) into plant assimilable $\mathrm{N}$ such as ammonia through a cascade of reactions between prokaryotes and plants with the use of complex enzyme systems (Wilson and Burris 1947). Inside the symbiotic root nodules, the bacteria reduce nitrogen to ammonia and supply it to the host (Denarie et al., 1996). This interaction starts with a signal exchange between both partners. Plant roots secrete specific flavonoids that interact with the bacterial NodD protein, resulting in the activation of rhizobial nod genes (nifH gene) and synthesis of Nod factors (Oldroyd, 2013). The nifH gene codes for the dinitrogenase reductase, one of the subunits of the nitrogenase complex, responsible for reducing atmospheric nitrogen into ammonia (Fischer, 1994).

The ability of PGPR to colonize roots in the presence of competing indigenous soil microflora is a major key to success in inoculation with beneficial bacteria.The PGP R. leguminosarum biovar trifolii R39, isolated from red clover nodules colonized the rhizospheres of pea, maize, and sugar beet better than the PGPR strain Pseudomonas fluorescens PsIA12 isolated from a wheat rhizosphere (Höflich et al., 1995). Yield increases caused by inoculation of nonlegumes with PGPR rhizobia have been reported in pot and field experiments. R. leguminosarum biovar trifolii R39 promoted the growth of maize, spring wheat, and spring barley in field trials performed between 1985 and 1993 in a loamy sand soil resulted in yields that were significantly $(\mathrm{P}<0.05)$ increased by 6 to $8 \%$ in Germany (Höflich et al., 1994).

The beneficial effects resulting from the use of legumes in crop rotations or in intercropping systems have conventionally been attributed to their ability to form atmospheric nitrogen fixing symbioses with rhizobia and other rotational benefits relating to disease suppression (Graham and Vance, 2000). This symbiotic N contribution is reported to benefit the cereal crops, such as maize, rice, wheat and sorghum with a relative yield increase of 11-35.3 \% (Peoples and Cranswell 1992). Moreover Mehboob et al. (2012) could have been shown the capacity of rhizobia in inducing the plant growth of non leguminous plants. In this regard, $A z o-$ rhizobium caulinodans (endophytic rhizobia) is known to enter the root system of cereals, other non-legume crops and Arabidopsis, by intercellular invasion between epidermal cells and to internally colonize the plant intercellularly, including the xylem (Cocking et al., 1994).

Legume crops substantially reduce the $\mathrm{N}$ requirement from external sources (Bhattacharyya and Jha 2012). However, N fixation efficiency of legumes varies, and depends on the host genotype, rhizobial efficiency, soil conditions, and climatic factors (Peoples and Cranswell 1992).

Nitrification is an important process in nitrogen cycle in which ammonia is converted to nitrite and nitrate by nitrifying bacteria such as Nitrosomonas and Nitrobacter. The nitrification products, nitrite and nitrate, are lost by denitrification (Parker 1972). It had been demonstrated that nitrification inhibitor produced by B. humidicola as root extracts were seen to inhibit nitrifying bacteria, with no adverse effects on other soil microorganisms such as Azospirillum lipoferum, R. leguminosarum and Azotobacter chroococcum (Gopalakrishnan et al. 2009).

Nitrification and denitrification remain to be the only known biological processes that generate nitrous oxide $\left(\mathrm{N}_{2} \mathrm{O}\right)$, a powerful greenhouse gas contribute to global warming. Therefore, biological nitrification inhibition is seen as the only major mitigation process towards global warming besides improving $\mathrm{N}$ recovery and $\mathrm{N}$ use efficiency of agricultural systems (Subbarao et al. 2012). However BNF ability, Nitrogen self sustainability and protein-rich grains of legumes require high energy and productivity tradeoffs (Hall 2004).

Moreover, various environmental factors limit nitrogen fixation, such as soil moisture deficiency, osmotic stress, extremes of temperature, soil salinity, soil acidity, alkalinity, nutrient deficiency, over doses of fertilizers and pesticides are an important driver for BNF (Zahran 1999).

\subsection{Siderophore Formation}

Microorganisms also enhance plant growth by scavenging available iron $\left(\mathrm{Fe}^{3+}\right)$, which involves secretion of high affinity, low molecular weight iron chelating ligands called siderophores (Anitha and Kumudini, 2014).Under aerobic environments, iron exists as insoluble hydroxides and oxyhydroxides which are not accessible to both plants and microbes (Rajkumar et al. 2010). It can occur in either as divalent (ferrous or $\mathrm{Fe}^{2+}$ ) or trivalent (ferric or $\mathrm{Fe}^{3+)}$ states which is determined by the $\mathrm{pH}$ and Eh (redox potential) of the soil 
(Bodek et al. 1988). Bacteria have the ability to synthesis low molecular weight compounds termed as siderophores, capable of sequestering $\mathrm{Fe}^{3+}\left(\right.$ ferric or $\left.\mathrm{Fe}^{3+}\right)$. These siderophores are known to have high affinity for $\mathrm{Fe}^{3+}$, and thus makes the iron available for plants. The siderophores are water soluble and are of two types viz. extracellular and intracellular. Ferric $\left(\mathrm{Fe}^{3+}\right)$ ions are reduced to ferrous $\left(\mathrm{Fe}^{2+}\right)$ and released into the cells by gram positive and negative rhizobacteria; resulting in destruction or recycling of siderophores (Rajkumar et al. 2010). Siderophores can form stable complex compounds with heavy metals such as $\mathrm{Al}, \mathrm{Cd}, \mathrm{Cu}$ etc. and with radionucleides including Uranium, Nitrogen and Phosphorus (Neubauer et al. 2000). Thus, the siderophore producing bacteria can relieve plants from heavy metal stress and assist in iron uptake.

Like other PGPR, rhizobia produce siderophores that are strain specific (Reigh and O'Connell, 1993), and they can utilize a large spectrum of these molecules to overcome iron starvation (Carson et al., 2000). Groups of rhizobia reported to produce siderophores include R. meliloti, R. tropici, R. leguminosarum biovar viciae, R. leguminosarum biovar trifolii, R.leguminosarum biovar phaseoli, Sinorhizobium meliloti and Bradyrhizobium sp.(Arora et al. 2001).

Plessner et al., (1993) was indicated that the future research will elucidate the importance of rhizobial siderophores in the biological control of pathogens and the possible competitive advantage gained by rhizobia through their ability to utilize siderophores of other organisms.

\subsection{Phosphate Solubilization}

Next to Nitrogen, phosphorus $(\mathrm{P})$ is the most crucial nutrient for plant growth. It exists in both inorganic and organic forms and the concentration depends on the parental material (Gray and Murphy 2002). Although the parent material has a strong control over the soil phosphorus status of terrestrial ecosystems (Buol and Eswaran 2000), the availability of phosphorus to plants is influenced by $\mathrm{pH}$, compaction, aeration, moisture, temperature, texture and organic matter of soils, crop residues, extent of plant root systems and root exudate secretions and available soil microbes. Soil microbes help in phosphorus release to the plants that absorb only the soluble phosphorus like monobasic $\left(\mathrm{H}_{2} \mathrm{PO}_{4}{ }^{-}\right)$and dibasic $\left(\mathrm{H}_{2} \mathrm{PO}_{4}{ }^{2-}\right)$ forms (Bhattacharyya and Jha 2012). The soil solution remains to be the main source of phosphorus supply to plants. The phosphorus content of agricultural soil solutions are typically in the range of $0.01-3.0 \mathrm{mgL}^{-1}$ representing a small portion of plant needs. The rest must be obtained from the solid phase through intervention of biotic and abiotic processes where the phosphate solubilizing activity of the microbes has a role to play (Sharma et al. 2013).

Some bacterial strains are found to possess both solubilization and mineralization capacity (Tao et al. 2008). Importance of this phosphorus solubilizing capacity in enhancing plant growth by Mesorhizobium mediterraneum has been demonstrated in chickpea and barley plants (Peix et al. 2001). Rhizobia, including $R$. leguminosarum, R. meliloti, M. mediterraneum, Bradyrhizobium sp. and B. japonicum (Afzal and Bano 2008) are the potential phosphorus solubilizers. These rhizobium synthesize low molecular organic acids which acts on inorganic phosphorous. For instance, 2-ketogluconic acid with a phosphate-solubilizing ability has been identified in R. leguminosarum (Halder et al. 1990) and R. meliloti (Halder and Chakrabarty 1993).

\subsection{Phytohormone Production}

As symbiotic partner, in addition to nitrogen supply, rhizobium also produces phytohormones, mainly including cytokinins, Indole-3-acetic acid (IAA), auxins, abscisic acid, gibberellins, and ethylene to induce some important physiological responses at different stages of plant development at low concentrations (Ma et al. 2008).

\subsubsection{Cytokinins}

Cytokinin is known to stimulates plant cell division and in some instances root development and root hair formation (Frankenberger and Arshad 1995). It is documented that $90 \%$ of rhizospheric microorganisms are capable of releasing cytokinins and about 30 growth-promoting compounds of the cytokinin group has been identified from microbial origin (Nieto and Frankenberger, 1991). Rhizobium strains are also reported 
as the potent producers of cytokinins (Senthilkumar et al. 2009).The prominent producers of Cytokinins are S. meliloti, S. fredii, S. medicae, and Mesorhizobium loti(Anna et al.2013).

\subsubsection{Indole-3-Acetic Acid (IAA)}

Indole-3-acetic acid is considered to be the best categorized auxin found in plants. IAA is known to enhance cell elongation, cell division and differentiation in plants (Singh et al. 2013). It has been estimated that $80 \%$ of bacteria isolated from the rhizosphere can produce IAA (Patten and Glick 1996). The prominent producers of IAA are Azorhizobium caulinodans, B.japonicum, B. elkanii, Mesorhizobium loti, R. japonicum, R. leguminosarum, R. lupine, R. meliloti, R. phaseoli, R. trifolii and Sinorhizobium spp. (Afzal and Bano 2008).

IAA production in rhizobium takes place via indole-3-pyruvic acid and indole-3-acetic aldehyde pathway. On inoculation of R. leguminosarum biovar Viciae, 60-fold increase in IAA was observed in the nodules of vetch roots (Camerini et al. 2008). One of the highest productions of IAA had been reported with the inoculation with B. japonicum-SB1 and with B. thuringiensis-KR1 (Mishra et al. 2009). Both environmental stress factors (acidic $\mathrm{pH}$, osmotic and matrix stress and carbon limitation) and genetic factors (auxin biosynthesis genes and the mode of expression) were shown to influence the biosynthesis of IAA (Spaepen and Vanderleyden 2011).

\subsubsection{Gibberellins}

Gibberellic acid is a plant growth regulator of economic and industrial importance (Bandelier et al.1997).Various gibberellins are available and are associated with several plant growth and development processes, such as seed germination, stem elongation, sex expression of flowers and fruit development (Boğa et al. 2009). It is also believed that certain types of dwarfness are due to gibberellins deficiency, but it has no effect on roots. Application of gibberellins is known to promote securing of the plants, parthenocarpy in fruits, increase fruit size and number of buds and break down the tuber dormancy. Many PGP microbes are reported to produce gibberellins (Dobbelaere et al. 2003) including Rhizobium and Sinorhizobium meliloti (Boiero et al. 2007).

\subsubsection{Abscisic Acid}

Abscisic acid in plants is synthesized partially in the chloroplasts and the whole biosynthesis primarily takesplace in the leaves. The production of abscisic acid is affeted by stresses such as water deficit and freezing temperatures. It is believed that biosynthesis occurs indirectly through the production of carotenoids. The transport of abscisic acid can occur in both xylem and phloem tissues and can also be translocated through paranchyma cells. The movement of abscisic acid in plants does not exhibit polarity like auxins (Walton and Li 1995).

Abscisic acid was reported to stimulate the stomatal closure, inhibit shoot growth while not affecting or even promoting root growth, induce seeds to store proteins and in dormancy, induce gene transcription for proteinase inhibitors and thereby provide pathogen defense and counteract with gibberellins (Davies 1995). Boiero et al. (2007) reported that Rhizobium sp. and B. japonicum produced abscisic acid.

\subsubsection{1-Aminocyclopropane-1-Aarboxylic Acid (ACC) Deaminase}

ACC deaminase is a member of a large group of enzyme that utilizes vitamin B6 and considered to be under tryptophan synthase family. Rhizobia have the ability to uptake ACC and convert it into $\alpha$-ketobutyrate and $\mathrm{NH}_{3}$. Hence, on inoculation of rhizobia producing ACC deaminase, the plant ethylene levels are lowered and result in longer roots providing relief from stresses, such as heavy metals, pathogens, drought, radiation, salinity, etc.

Rhizobial strains that express ACC deaminase are up to $40 \%$ more efficient at forming nitrogen-fixing nodules than strains that lack this activity (Ma et al. 2004). However, strains of rhizobia that express ACC deaminase have only a low level of enzyme activiity compared with free-living plant growth-promoting bacteria, i.e.typically around $2-10 \%$. Thus, free-living bacteria bind relatively non-specifically to plant 
tissues (mainly roots) and have a high level of ACC deaminase activity that can protect plants from different abiotic and biotic stresses by lowering ethylene levels throughout the plant. The common mode of acdS transcriptional regulation genes from various strains of Mesorhizobium loti have been found to be under the transcriptional control of the nifA promoter that is normally responsible for activating the transcription of nif, nitrogen fixation genes (Nascimento et al. 2012a). Moreover, Nascimento et al. (2012a) suggested that in many Mesorhizobium spp. acdS genes appear to be horizontally transferred between strains by the exchange of the symbiosis island. This suggestion is based on observing the presence of the acdS gene in the symbiosis islands of M. loti R7A, M. sp. MAFF303099, Mesorhizobium ciceri bv.biserrulae WSM1271, Mesorhizobium australicumWSM2073T and Mesorhizobium opportunistum WSM2075T, close to the nitrogen fixation gene cluster.

Strains, such as R. leguminosarum bv.viciae, R. hedysari, R. japonicum, R. gallicum, B. japonicum, B. elkani, Mesorhizobium loti and $S$. meliloti also had been known to produce ACC deaminase (Duan et al. 2009).Inoculation with these bacteria had shown to promote root elongation, shoot growth, enhanced rhizobial nodulation and minerals uptake (Glick, 2012).

\subsection{Synergistic Effects of Rhizobial Dual Inoculation}

A range of PGP microbes can be used with rhizobium that not only improves legume growth and yield but also cost effective and efficient. Certain specific dual inoculation causes synergy by functioning as helper bacteria to improve the performance of the other bacteria (Bashan and de Bashan 2005). Therefore in such co-inoculations, the combination of PGP bacteria, rhizobia and the host genotype has to be selected after extensively careful evaluations (Remans et al. 2008).

Azospirillum, the free living diazotroph, Azotobacter, Bacillus, Psuedomonas, Serretia, and Enterobacter are some of the genera that are successfully used with rhizobium as co-inoculants. Azospirillum was found to enhance growth and yield of several leguminous crops upon inoculation (Roseline et al. 2008). Improved nodulation was found when Azospirillum lipoferum and R. leguminosarum biovar trifolii were co-inoculated in white clovers (Tchebotar et al. 1998), pigeonpea and chickpea (Deanand et al. 2002). It was found that Azospirillum can increase the infection site providing a space for rhizobium resulting in higher nodule formation (Tchebolas et al. 1988).Moreover, co-inoculation with Azospirillum and Rhizobium were shown to increase phytohormones, vitamins and siderophore production (Cassan et al. 2009). Co-inoculation of common bean with Azospirillum- rhizobium was also shown to increase the fixed nitrogen quantity (Reman et al. 2008). Azotobacter was found to be a potential co-inoculant with rhizobium that enhanced the production of phytohormones and vitamins and increase the nodulation (Akhtar et al. 2012).

Enhanced nodulation and nitrogen fixation was noticed upon inoculation of Bacillus and Azospirillum sp.along with rhizobial inoculants in pigeonpea (Rajendran et al. 2008). Interaction between Streptomyces lydius WYEC108 and rhizobium of pea were shown to promote growth of the plant (Tokala et al. 2002) including nodule number and growth, probably by the root and nodule colonization of Streptomyces. Enterobacter is another most abundant PGP bacterium that increased the yield of nodules on green gram when co-inoculated with Bradyrhizobium sp. (Gupta et al. 1998).

Recently, it was found that nodulation, root and shoot dry weight, grain and straw yield, nitrogen and phosphorus uptake were significantly increased in chickpea upon co-inoculation with Mesorhizobium sp. and Psuedomonas aeruginosa (Verma et al. 2013). Similar plant growth effects along with the antagonistic activities against F. oxysporum and R. solani has been observed on chickpea by co-inoculation of Mesorhizobium, Azotobacter chroococcum, P. aeruginosa and Trichoderma harzianum (Verma et al. 2014).

\subsection{Bio-Control Abilities of Rhizobia}

One of the functions associated with soil microorganisms is disease suppression and protection of plants from disease when pathogens are present. The ability of bacterial siderophores and antibiotics to suppress phytopathogens could be the significant agronomic importance. Both mechanisms have essential functions in microbial antagonism but also the mechanisms leads to elicit induced resistance. Resistance-inducing and antagonistic rhizobacteria might be useful in formulating new inoculants, offering an attractive alternate of environmentally friendly biological control of plant disease and improving the cropping 
systems into which it can be most profitably applied (Beneduzi et al. 2012).

Siderophore is one of the biocontrol mechanisms belonging to PGPR groups under iron limiting condition. Rhizobial strains also compete for nutrients by displacing the pathogens. Rhizobia starve the pathogens of available iron by producing high affinity siderophores and thereby limit the growth of the pathogen (Arora et al. 2001). Therefore, the low availability of iron in the environment would suppress the growth of pathogenic organisms including plant pathogenic fungi (Whipps, 2001).In addition to siderophore, there are other mechanisms of biocontrol including antibiotic compounds, elicitation of induced systemic resistance (ISR) of plant, and lytic enzyme secretion (Haas and Defago, 2005).

Production of volatiles such as hydrogen cyanide, suppress the growth of fungal pathogens; the ability to successfully compete with pathogens for nutrients or specific niches on the root; and the ability to induce systemic resistance (ISR) (Compant et al., 2005). Several rhizobial strains are reported to have the bio-control properties. Hence, usage of these strains against soil borne pathogens can lead to potential control.

The mechanisms of bio-control by rhizobia includes, competition for nutrients (Arora et al. 2001), production of antibiotics (Chandra et al. 2007), production of enzymes to degrade cell walls (Ozkoc and Deliveli 2001) and production of siderophores (Deshwal et al. 2003b). Hydrogen cyanide (HCN) synthesized by some rhizobacteria inhibits diseases in plant and thereby increasing the biocontrol mechanism (Schippers, 1990).The production of metabolites such as HCN, phenazines, pyrrolnitrin, viscoinamide and tensin by rhizobia are also reported as other mechanisms (Bhattacharyya and Jha 2012). For example, the strains including R. leguminosarum biovar trifolii, R. leguminosarum biovar viciae, R. meliloti, R. trifolii, S. meliloti and B. japonicum have been reported to secrete antibiotics and cell-wall degrading enzymes that can inhibit the phytopathogens (Ozkoc and Deliveli 2001). For example, a study on colonization behavior of $P$. fluorescens and S. meliloti in alfalfa rhizosphere had sufficiently demonstrated the usage of biocontrol agents to suppress pathogens (Villacieros et al. 2003). Pathogens that infect okra and sunflower, such as Macrophomina phaseolina, Rhizoctonia solani and Fusarium solani were shown to be controlled with the usage of B. japonicum, R. meliloti and R. leguminosarum (Ozkoc and Deliveli, 2001). Some more examples are cyst nematode of potato controlled by R. etli strain G12 (Reitz et al. 2000), Pythium root rot of sugar beet by R. leguminosarum viciae (Bardin et al. 2004) white rot disease in Brassica campestris by M. loti and sheath blight of rice by R. leguminosarum biovar (Mishra et al. 2006). Bradyrhizobium sp. had been shown to control the infection of M. phaseolina in peanut, while enhancing seed germination, nodule number and grain yield (Deshwal et al. 2003b).

\subsection{Induction of Plant Resistance}

The plant growth promoting strains have been confirmed to trigger the resistance of plants against pathogens, by process known as induced systemic resistance (ISR). In this process, a signal is generated involving jasmonate or ethylene pathway and thus inducing the host plant's defense response. Various rhizobial species are reported to induce systemic resistance in plants by producing bio-stimulatory agents including R. etli, R. leguminosarum biovar phaseoli and R. leguminosarum biovar trifolii (Mishra et al. 2006). Even individual cellular components of the rhizobium had been shown to induce ISR viz. lipopolysaccharides, flagella, cyclic lipopeptides, homoserine lactones, acetoin and butanediol (Lugtenberg and Kamilova 2009).

\section{ADAPTATION TO ECOPHSIOLOGICAL STRESS}

\subsection{Tolerance to Extremes of Temperature}

The growth and survival of rhizobia in soils are adversely affected by high soil temperatures (Meghvansi, 2006).Temperature stress alters the permeability of the membrane and causes denaturation of certain enzymes/proteins leading to the death/poor growth of the rhizobia. High temperatures lead to increased drought intensity, due to enhanced transpirational water loss. This can lead to delay in nodulation or restrict the nodule to the subsurface region, reduction in nodule number, rhizobial growth, rate of colonization and infectious events (Munns et al.1979). The optimum temperature for rhizobial growth is $28-31^{\circ} \mathrm{C}$, while many of them are unable to grow beyond $37^{\circ} \mathrm{C}$. However, rhizobia isolated from hot and 
dry environments of the Sahel Savannah are reported to tolerate temperature up to $45^{0} \mathrm{C}$, but they were found to lose their infectiveness (Karanja and Wood 1988). Similarly, a heat treatment of 35 and $37^{\circ} \mathrm{C}$ to $R$. phaseoli was found to cause loss of melanin synthesis plasmid DNA and symbiotic properties (Beltra et al. 1988). In contrast, at 35 and $38^{\circ} \mathrm{C}, R$. leguminosarum biovar phaseoli was found to be effective and formed nodules in Proteus vulgaris, but these nodules were found to remain ineffective (Hungria and Franco 1993). Upon exposing the wild and heat resistant Rhizobium sp. to 30 and $43^{\circ} \mathrm{C}$, changes in the cell surface including extracellular polymeric substances/exo polysaccharides (EPS), lipopolysaccharide (LPS) and proteins had been demonstrated (Nandal et al. 2005).

Intra species difference in competitive efficiency was demonstrated by Krasova-Wade et al. (2006) in which Bradyrhizobium ORS 3257 was found to compete their best under favorable water conditions while Bradyrhizobium ORS 3260 was the best under limited water conditions.

\subsection{Salinity Stress}

Salinity is known to be the higher concentration of ions $\left(\mathrm{Na}^{+}, \mathrm{Cl}^{-}, \mathrm{SO}_{4}\right.$ nutrient supply via photosynthesis products and oxygen consumption) and BNF (by reducing the nodule metabolism, leghemoglobin content and atmospheric nitrogen diffusion). One of the major problems in semi-arid regions is increased salinity levels of the soil. Application of salinity tolerant rhizobia in legume cropping area helps in the formation of effective nodules and efficient nitrogen fixation. Symbiotic effectiveness depends on the specific combination of compatible legume and rhizobium under the saline conditions (Faghire et al., 2013).

Salinity decreases the nutrition uptake of plants, particularly phosphorus, due to their binding with Calcium ions in salt-stressed soils.

Rhizobial species are known to vary in their salt sensitivity. Some of them are categorized as salt tolerant, such as R. meliloti (Zhang et al. 1991), R. fredii (Yelton et al. 1983), Rhizobium sp. from Acacia senegal, Prosopis chilensis (Zahran et al. 1994) and Vigna unguiculata (Mpepereki and Makoneses 1997), chickpea, soybean (El Sheikh and Wood 1990), and pigeonpea (Subbarao et al. 1990) whereas others as salt sensitive such as R. leguminosarum (Chein et al. 1992). The existence of a high degree of phenotypic and genotypic diversity in Sinorhizobium populations sampled from marginal soils of arid and semi-arid regions of Morocco have been demonstrated recently (Thami-Alami et al. 2010).

The effect of salt stress on halotolerant rhizobia by their LPS (Lloret et al. 1995), protein profiles (Saxena et al. 1996) and exopolysaccharide (Lloret et al. 1998) have been studied. Large variability in the efficiency of host plant and rhizobial strains on BNF under salinity had been reported (Jebara et al. 2001).

Salt tolerance mechanisms involve several gene families which have been reported largely in $S$. meliloti followed by R. etli, R. tropici, Rhizobium sp., Sinorhizobium fredi and B. japonicum. Osmoprotectants, the compatible solutes/osmolytes play a dual role as evidenced in S. meliloti by proline-betaine which serves as both osmoprotectant (under high osmotic stress) and energy source (under low osmotic stress) (Miller-Williams et al. 2006).

\section{4. pH Tolerance}

Soil $\mathrm{pH}$ influences the growth and survival of rhizobia through alteration in the permeability of the membrane and uptake of nutrients. Neutral $\mathrm{pH}$ allows the uptake of appropriate amount of nutrients and results in optimum growth of rhizobia (Bhargava et al. 2016). Low survival and poor growth of rhizobia and inhibition of initiation and formation of root nodules are the important responses that lead to the failure of rhizobia-legume symbiosis in acid soils (Richardson et al. 1988). The addition of lime on acid soils has been followed as a common practice to raise the soil $\mathrm{pH}$ creating a favorable condition for the growth and survival of root nodule bacteria (Watkin et al. 1997).

Graham et al. (1994) proposed some strains of Rhizobium, Azorhizobium and Bradyrhizobium to be low pH tolerant. Tolerance to acidity by rhizobia was correlated with the production of extracellular polysaccharide or polyamines glutamate concentration in the cell. Muglia et al. (2007) highlighted the role of glutathione, a tripeptide for the growth of $R$. tropici under low $\mathrm{pH}$ conditions. Watkin et al. (2003) 
reported the ability of acid tolerant $R$. leguminosarum biovar trifolii in accumulating higher level of potassium and phosphorous than an acid sensitive strain.

\subsection{Tolerance to Heavy Metals}

Heavy metals are the key pollutants causing serious illness to plants, ecosystem and humans by their non-degradable nature. For the reclamation and removal of heavy metals, phytoremediation is suggested to be practiced as it preserves natural soil properties and microbial biomass (Gianfreda and Rao 2004). Ma et al. (2011) were also proposed the use of microorganisms such as Bacillus sp., Pseudomonas sp., Azotobacter sp., Enterobacter sp., and Rhizobium sp. to speed up the phytoremediation process.

Rhizobia multiply slowly in soil until they infect a compatible host. Rapid growth of rhizobia occurs only after successful infection by a single cell and formation of a nitrogen-fixing nodule on the host-root (Downie, 1997). In heavy metal contaminated sites, after the successful establishment of symbiosis with the host plant, the heavy metals tend to accumulate in the nodules. Effects of heavy metals on growth, abundance, morphology and physiology of various strains of $R$. leguminosarum have been well documented (Lakzian et al. 2002). However, despite demonstrating the extent of benefits through the use of PGPR in remediation of contaminated sites, there had been very few field studies while most of the successful studies are either from greenhouse or growth chambers (Lucy et al. 2004). Continuous exposure to heavy metals leads the viable bacterial cells not only to transform into a non-viable form, but also adversely affects the genetic diversity and nodulation of the host plants (Paton et al. 1997). Reductions in bacterial counts of rhizobium sp. have been reported with the increasing concentrations of heavy metals such as $\mathrm{Cu}, \mathrm{Zn}$ and $\mathrm{Pb}$, either sole or in combinations, and variations in the expression of symbiotic genes including nod genes (Stan et al. 2011). A great diversity in terms of plasmid types has been observed in isolates of un-polluted soil than the isolates from polluted soils. In addition, the dominant plasmid groups present in un-polluted soils were found to be absent in isolates of polluted soils and vice versa (Castro et al. 1997). Changes in physiology were found to lead to the variations in protein profiles that serve as a marker for stress response analysis in R. leguminosarum biovar viciae isolated from heavy metal polluted sites (Pereira et al. 2006a).

Similar to the non-nodulating bacterial species, rhizobia also has its own features such as EPS and LPS for influencing heavy metal resistance. EPS are biopolymers that possess negatively charged ligands which instantly form complexes with metal ions through electrostatic interactions (Sutherland 2001). Lakzian et al. (2002) identified that plasmids are the major contributing factor for this as highly tolerant strains were noticed to have 6-9 plasmids whereas moderately tolerant strains have only three plasmids. EPS from Rhizobium Etli (strain M4), isolated from an acid mine drainage, was shown to impact ecosystem near a manganese mine in Northern Australia (Pulsawat et al. 2003). However, an alternate view was reported by Pereira et al. (2006b) on cadmium (Cd) resistance as they found similar number (a maximum of four) plasmids in all the tolerant, moderately tolerant and sensitive isolates.

Rhizobia, such as R. fredii, R. meliloti, R. etli, R. leguminosarum biovar viceae, R. leguminosarum biovar trifolii, Bradyrhizobium sp. and B. japonicum had been evaluated for heavy metal resistance and of which $R$. fredii and R. meliloti alone were found to exhibit higher metal tolerance against Tellurium (Te) and Selenium (Se) (Kinkle et al. 1994). Nonnoi et al. (2012) demonstrated differences in the heavy metal resistance spectrum of S. medicae and R. leguminosarum biovar trifolii strains isolated from mercury-contaminated soils. Paudyal et al. (2007) reported the negative effect of heavy metals such as $\mathrm{Al}$, Fe and Mo on two Rhizobium strains and their symbiotic efficiency on host plants. Chaudri et al. (2000) observed greatly reduced symbiosis of $R$. leguminosarum biovar viciae with pea and R. leguminosarum biovar trifolii with white clover under $\mathrm{Zn}$ toxicity as a consequence of reduced numbers of free living rhizobia in the soil indirectly affecting $\mathrm{N}$ fixation and $\mathrm{Zn}$ phytotoxicity.

\subsection{Pesticide tolerance of Rhizobia}

Pesticide affects plant growth by altering plant root's architecture, number of root sites for rhizobial infection, transformation of ammonia into nitrates, transformation of microbial compounds to plants and vice versa. Besides this growth and activity of free living or endophytic nitrogen fixing bacteria has also 
been affected (Mathur 1999). Several studies have documented the effects of various pesticides on the reduction of microbial diversity and density on various soil types (Martinez-Toledo et al. 1996). Numerous microorganisms have the capacity to degrade the pesticides by the action of degradative genes in plasmids/transposons/chromosomes (Kumar et al. 1996). In addition to Nitrogen fixation, rhizobia are also reported to degrade toxic pesticides to non-toxic forms (Ahemad et al.2009), synthesise antifungal compounds (Zaidi et al. 2009). Therefore, identifying rhizobia possessing multiple growth-promoting activities and exhibiting insecticide tolerance ability is useful in optimising the yields of grain legumes in both conventional and stressed production systems. Among insecticides, the broad-spectrum insecticides fipronil and pyriproxyfen are used to control insects such as locusts, ticks, whiteflies, houseflies and mosquitoes, both at larval and adult stages (Aajoud et al. 2003) at low field application rates (Bobe et al. 1997) for various crops including legumes. The fipronil and pyriproxyfen-tolerant Rhizobium sp. strain MRL3 produced plant-growth-promoting substances in substantial amounts, both in the presence and in the absence of the insecticides. Interestingly, when applied with any concentration of the two insecticides, Rhizobium sp. strain MRL3 significantly increased the measured parameters compared with plants grown in soils treated solely with the same concentration of each insecticide but without inoculants (Ahemad and Khan, 2011).

\subsection{Tolerance to Antibiotics}

Antibiosis is the most studied and widely used mechanism of biocontrol activities (Gupta et al., 2001). It refers to the inhibition of pathogen by the metabolic products released through the antagonist secondary metabolic pathways. These products include volatile compounds, toxic compounds and antibiotics, which are deleterious to the growth or metabolic activities of other microorganism at low concentrations (Fravel, 1988).

Although antibiotic resistance in bacteria is a threat in the health sector (Wright, 2007), it is a desirable trait in both indigenous and introduced rhizobial populations (Anand et al.2012). Resistance to antibiotics increases the rhizobium's chances of survival in the rhizosphere. The antibiotic-resistant rhizobium makes itself competitive in soil environment to occupy high number of nodules in legumes (Belachew 2010). Large differences in degree of tolerance to antibiotics among fast and slow-growing rhizobia have been reported (Frioni et al. 2001).

Rhizobial strains should be resistant to concentrations of antibiotics that inhibit the growth of other soil bacteria and they should be able to retain their infectivity and symbiotic effectiveness. While the majority of rhizobial strains in the soil are susceptible to antibiotics, others have developed resistance in response to naturally produced antibiotics (Xavier et al.1998). The resistance may be developed towards one or multiple antibiotic classes (Anand et al.2012). Cole and Elkan (1973) reported that R. japonicum (now Bradyrhizobium japonicum) carries extra chromosomal antibiotic resistance genes.

It was demonstrated early by Balassa (1963) that acquisition of resistance to streptomycin by three rhizobial species (R. japonicum, $R$. meliloti and $R$. lupini) is through transformation and later acquisition of penicillin resistance genes by $R$. phaseolus and $R$. leguminosarum strains through transformation was also reported (Gadre et al.1967). Later on in $R$. etli, the existence of rhizobium multiresistance genes ( $\mathrm{rmrA}$ and $\mathrm{rmrB}$ ) against phytoalexin and salicylic acids were identified (Gonzalez-Pasayo and Martinez-Rpmero 2000). In general rhizobial strains reported to develop antibiotic resistance includes $R$. leguminosarum, $R$. trifolii, $R$. meliloti, R. Japonicum, R. phaseolus, R. lupini, and R. etli, (Naamala et al.2016)

\section{CONCLUSION}

Rhizosphere is a unique niche that provides habitation and nutrition to PGP microorganisms. In turn, these microorganisms produce multiple benefits of induced plant growth, defense against diseases and survival under stress with many other unknown benefits.

Rhizobia in addition to the nitrogen supply, they promote growth of the plant as a symbiotic partner and soil microbe in a number of ways. Plant growth could be induced by rhizobia through some of their growth stimulating mechanisms such as mobilization of nutrient, enhancement in stress resistance, solubilization of phosphates, production of phytohormones and siderophores (Ahmad et al., 2008). 
Symbiotically produced IAA alone or along with other plant hormones involved in several stages of establishment of symbiotic relationship and also transported to the plant for its use. Rhizobial induced local accumulation of auxins stimulates the formation of nodule primordial (Mortier et al.2012) and also necessary for growth and maintenance of root nodules. Combinations of beneficial bacterial strains that interact synergistically are currently being devised and numerous recent studies have shown a promising trend in the field of inoculation technology. PGP rhizobia are excellent model systems which can provide biotechnologist with novel genetic constituents and bioactive chemicals having diverse uses in agriculture and environmental sustainability.

Therefore, generation of comprehensive knowledge on screening strategies and intense selection of best rhizobial strain for rhizosphere competence and survival should be the current need to enhance the inoculums usage successes. Thus, additional comprehensive research to exploit the potential of PGP rhizobia would provide for expansion of this research area, commercialization and improve sustainability in agricultural production.

\section{References}

Adesemoye AO, Kloepper J (2009) Plant-microbes interactions in enhanced fertilizer-use efficiency. Applied Microbiology and Biotechnology 14: 1-12.

Ahmad, F., Ahmad, I. and Khan, M.S. (2008) Screening of Free-Living Rhizospheric Bacteria for Their Multiple Plant Growth Promoting Activities. Microbiological Research, 163, 173-181. http:/ /dx.doi.org/10.1016/j.micres.2006.04.001

Ahemad M, Khan MS, Zaidi A andWani PA, (2009) Remediation of herbicides contaminated soil using microbes, in Microbes in Sustainable Agriculture, ed. by Khan MS, Zaidi A and Musarrat J. Nova Science Publishers, New York, USA, pp. 261-284

Ahemad M, Khan MS (2011) Insecticide-tolerant and plant-growthpromoting Rhizobium improves the growth of lentil (Lens esculentus) in insecticide-stressed Soils. Pest Manag Sci; 67: 423-429

Ahemad M, Khan MS (2012c) Effects of pesticides on plant growth promoting traits of Mesorhizobium strain MRC4. J Saudi Soc Agric Sci 11:63-71

Aajoud A, Ravanel P and Tissut M, (2003) Fipronilmetabolism and dissipation in a simplified aquatic ecosystem. J Agric Food Chem 51:1347-1352.

Akhtar N, Qureshi MA, Iqbal A, Ahmad MJ, Khan KH (2012) Influence of Azotobacter and IAA on symbiotic performance of Rhizobium and yield parameters of lentil. J Agric Res 50:361-372.

Anna K., Carole L., Neil Emery R. J., and Florian F,(2013) Bioactive Cytokinins Are Selectively Secreted by Sinorhizobium meliloti Nodulating and Nonnodulating Strains; MPMI Vol. 26, No. 10, 2013, pp. 1225-1231

Anand A, Jaiswal SK, Dhar B, Vaishampayan A (2012) Surviving and thriving in terms of symbiotic performance of antibiotic and phage-resistant mutants of Bradyrhizobium of soybean [Glycine max (L.) Merrill]. Curr Microbiol 65:390-397

Anitha, G. and Kumudini, B. S. (2014) Isolation and characterization of fluorescent pseudomonads and their effect on plant growth promotion.Journal of Environmental biology, 35, 627-634.

Afzal A, Bano A (2008) Rhizobium and phosphate solubilizing bacteria improve the yield and phosphorus uptake in wheat (Triticum aestivum L.). Int J Agric Biol 10:85-88

Arora NK, Kang SC, Maheshwari DK (2001) Isolation of siderophore producing strains of Rhizobium meliloti and their biocontrol potential against Macrophomina phaseolina that causes charcoal rot of groundnut. Curr Sci 81:673-677

Balassa G (1963) Genetic transformation of Rhizobium: A review of the work of R. Balassa. Bacteriol Rev 27:22

Bandelier S, Renaud R, Durand A. (1997) Production of gibberellic acid by fed batch solid-state fermentation in an aseptic pilot scale reactor. Process Biochem 32: 141-145.

Bashan Y, de Bashan LE (2005) Bacterial plant growth promotion. In: Hillel D (ed) Encyclopedia of soils in the environment. Elsevier, Oxford, pp 103-115

Belachew T (2010) Intrinsic antibiotic resistance, survival of Rhizobium leguminosarum strains and fixation potential of pea varieties (Pisum sativum L.) in southeast Ethiopia. Int J Microbiol Res 2:75-79

Beltra R, Del-Solar G, Sanchez-Serrano JJ, Alonso E (1988) Mutants of Rhizobium phaseoli HM Mel (2) obtained by means of elevated temperatures. Zentbl Mikrobiol 143:529-532 
Beneduzi A, Ambrosini A, Luciane Passaglia MP (2012) Plant growth-promoting rhizobacteria (PGPR): Their potential as antagonists and biocontrol agents. Genetics and Molecular Biology 35: 1044-1051.

Berendsen RL, Pieterse CM, Bakker PAHM (2012). The rhizosphere microbiome and plant health. Trends in Plant Science 17: 478-486.

Bhargava1, Y., Murthy, J. S. R., Rajesh Kumar T. V., Narayana Rao M. (2016) Phenotypic, Stress Tolerance and Plant Growth Promoting Characteristics of Rhizobial Isolates from Selected Wild Legumes of Semiarid Region, Tirupati, India Advances in Microbiology, 6, 1-12

Bhattacharyya PN, Jha DK (2012) Plant growth-promoting Rhizobacteria (PGPR): emergence in agriculture. World J Microbiol Biotechnol 28:1327-1350

Bobe A, Coste CM and Cooper JF, (1997) Factors influencing the adsorption of fipronil in soils. J Agric Food Chem 45:4861-4865.

Bodek I, Lyman WJ, Reehl WF, Rosenblatt DH (1988) Environmental inorganic chemistry: properties, processes, and estimation methods. In: Walton BT, Conway RA (eds) SETAC special publication series. Pergamon Press, New York

Boğa A, Binokay S, Sertdemir Y. (2009) The toxicity and teratogenicity of gibberellic acid (GA3) based on the frog embryo teratogenesis assay-Xenopus (FETAX). Turk J Biol 33: 181188.

Boiero L, Perrig D, Masciarelli O, Penna C, Cassan F, Luna V (2007) Phytohormone production by three strains of Bradyrhizobium japonicum and possible physiological and technological implications. Appl Microbiol Biotechnol 74:874-880

Buol S, Eswaran H (2000) Oxisols. Adv Agron 68:151-195 Caba JM, Centeno ML, Fernandez B, Gresshoff PM, Ligero F (2000) Inoculation and nitrate alter phytohormone levels in soybean roots: differences between a super nodulating mutant and the wild type. Planta 211:98-104

Camerini S, Senatore B, Lonardo E, Imperlini E, Bianco C, Moschetti G, Rotino GL, Campion B, Defez R (2008) Introduction of a novel pathway for IAA biosynthesis to rhizobia alters vetch root nodule development. Arch Microbiol 190:67-77

Cassan F, Perrig D, Sgroy V, Masciarelli O, Penna C, Luna V (2009) Azospirillum brasilense Az39 and $\quad$ Bradyrhizobium japonicum E109, inoculated singly or in combination, promote seed germination and early seedling growth in corn (Zea mays L.) and soybean (Glycine max L.). Eur J Soil Biol 45:28-35

Castro IV, Ferreira EM, McGrath SP (1997) Effectiveness and genetic diversity of Rhizobium leguminosarum bv. trifolii isolates in Portuguese soils polluted by industrial effluents. Soil Biol Biochem 29:1209-1213

Chaudri AM, Allain CMG, Barbosa-Jefferson VL, Nicholson FA, Chambers BJ, McGrath SP (2000) A study of the impacts of $\mathrm{Zn}$ and $\mathrm{Cu}$ on two rhizobial species in soils of a long-term field experiment. Plant Soil 221:167-179

Chein CT, Maundu J, Cavaness J, Daudurand LM, Orser CS (1992) Characterization of salt-tolerant and salt-sensitive mutants of Rhizobium leguminosarum biovar viciae strain C1204b. FEMS Microbiol Lett 90:135-140

Cocking E C,Webster G, Batchelor C A and Davey M R (1994) Nodulation of non-legume crops. A new look. Agro-Food-Industry Hi-Tech. Jan 21-24.

Cole MA, Elkan GH (1973) Transmissible resistance to penicillin G, neomycin, and chloramphenicol in Rhizobium japonicum. Antimicrob Agents Chemother 4:248-253

Compant S, Duffy B, Nowak J, Clement C, Barka EA. (2005) Use of plant growth promoting bacteria for biocontrol of plant diseases: principles, mechanisms of action, and future prospects. Appl Environ Microbiol;71:4951-9.

Davies PJ (1995) The plant hormones: their nature, occurrence and functions. In: Davies PJ (ed) Plant hormones: physiology, biochemistry and molecular biology. Kluwer Academic Publishers, Dordrecht, pp 1-12

Deanand BJ, Patil AB, Kulkaarni JH, Algawadi AR (2002) Effect of plant growth promoting rhizobacteria on growth and yield of pigeonpea (Cajanus cajan L.) by application of plant growth promoting rhizobacteria. Microbiol Res 159:371-394

Deshwal VK, Dubey RC, Maheshwari DK (2003a) Isolation of plant growth promoting strains of Bradyrhizobium (Arachis) sp. With biocontrol potential against Macrophomina phaseolina causing charcoal rot of peanut. Curr Sci 84:443-444

Downie A (1997) Fixing a symbiotic circle. Nature 387:352-353

El Sheikh EE, Wood M (1990) Salt effects on survival and multiplication of chickpea and soybean rhizobia. Soil Biol Biochem 22:343-347

Etesami, H., Hossein, A.A. and Abolfazl, A.A. (2009) Evaluation of Plant Growth Hormones Production (IAA) Ability by Iranian Soils Rhizobial Strains and Effects of Superior Strains Application on Wheat Growth Indexes. World Applied Sciences Journal, 6, 1576-1584. 
Faghire, M., Mohamed, F., Taoufiq, K., Fghire, R., Bargaz, A., Mandri, B., Oufdou, K., Laury, A., Drevon, J.J. and Ghoulam, C. (2013) Genotypic Variation of Nodules' Enzymatic Activities in Symbiotic Nitrogen Fixation among Common Bean (Phaseolus vulgaris L.) Genotypes Grown under Salinity Constraint. Symbiosis, 60, 115-122. http:/ / dx.doi.org/10.1007/s13199-013-0247-x

Fischer HM. (1994) Genetic regulation of nitrogen fixation in rhizobia. Microbiol Rev. 58:352-86.

Frankenberger WTJ, Arshad M (1995) Photohormones in soil: microbial production and function. Dekker, New York

Fravel D. (1988) Role of antibiosis in the biocontrol of plant diseases. Annu Rev Phytopathol; 26:75-91.

Frioni L, Rodriguez A, Meerhoff M (2001) Differentiation of rhizobia isolated from native legume trees in Uruguay. Appl Soil Ecol 16:275-282

Gadre S, Mazumdar L, Modi V, Parekh V (1967) Interspecific transformation in Rhizobium. Arch fu“r Mikrobiologie 57:388-391

Gianfreda L, Rao MA (2004) Potential of extra cellular enzymes in remediation of polluted soils: a review. Enzyme Microb Technol 35:339-354

Gonzalez-Pasayo R, Martinez-Rpmero E (2000) Multiresistance genes of Rhizobium etli CFN42. MPMI 13:572-577

Gopalakrishnan S, Watanabe T, Pearse SJ, Ito O, Hossian AKMZ, Subbarao GV (2009) Biological nitrification inhibition by Brachiaria humidicola roots varies with soil type and inhibits nitrifying bacteria, but not other major soil microorganisms. Soil Sci Plant Nutr 55:725-733

Graham PH, Draeger KJ, Ferrey ML, Conroy MJ, Hammer BE, Martı́nez E, Aarons SR, Quinto C (1994) Acid pH tolerance in strains of Rhizobium and Bradyrhizobium, and initial studies on the basis for acid tolerance of Rhizobium tropici UMR1899. Can J Microbiol 40:198-207

Graham, P.H. and Vance, C.P. (2000) Nitrogen fixation in perspective: an overview of research and extension needs. Field Crops Res. 65:93-106.

Gray J, Murphy B (2002) Parent material and world soil distribution, 17th world congress of soil science. Bangkok, Thailand

Glick BR (2012) Plant growth-promoting bacteria: mechanisms and applications. Scientifica, Article ID 963401. doi:http://dx.doi. org/10.6064/2012/963401

Gupta A, Saxena AK, Gopal M, Tilak KVBR (1998) Effect of plant growth promoting rhizobacteria on competitive ability of introduced Bradyrhizobium sp. (Vigna) for nodulation. Microbiol Res 153:113-117

Gupta CP, Dubey RC, Kang SC, Maheshwari DK.(2001).Antibiosis mediated necrotrophiceffect of Pseudomonas GRC2 against two fungal pathogens. Curr Sci;81:91-4.

Halder AK, Chakrabarty PK (1993) Solubilization of inorganic phosphate by Rhizobium. Folia Microbiol 38:325-330

Halder AK, Mishra AK, Bhattacharya P, Chakrabarthy PK (1990) Solubilization of rock phosphate by Rhizobium and Bradyrhizobium. J Gen Appl Microbiol 36:1-92

Hall AE (2004) Breeding for adaptation to drought and heat in cowpea. Eur J Agron 21:447-454

Haas D, Defago G (2005). Biological control of soil-borne pathogens by fluorescent pseudomonads. Nature. Rev. Microbiol., 1038: 1-13.

Hernandez-Lucas, I., Segovia, L., Martínez-Romero, E., and Pueppke, S.G. (1995). Appl. Environ. Microbiol. 61, 2775-2779.

Höflich, G., Wiehe, W., and Kühn, G. (1994) Plant growth stimulation by inoculation with the symbiotic and associative rhizosphere microorganisms. Experientia 50:897-905.

Höflich, G., Wiehe, W., and Hecht-Buchholz, C., (1995) Rhizosphere colonization of different crops with growth promoting Pseudomonas and Rhizobium bacteria. Microbiol. Res. 150:139-147

Hungria M, Franco AA (1993) Effects of high temperature on nodulation and nitrogen fixation by Phaseolus vulgaris L. Plant Soil 149:95-102

Jebara M, Mhamdi R, Aouani ME, Ghrir R, Mars M (2001) Genetic diversity of Sinorhizobium populations recovered from different Medicago varieties cultivated in Tunisian soils. Can J Microbiol 47:139-147

Karanja NK, Wood M (1988) Selecting Rhizobium phaseoli strains for use with beans (Phaseolus vulgaris L.) in Kenya. Tolerance of high temperature and antibiotic resistance. Plant Soil 112:15-22

Khan, M.S., Zaidi, A. and Wani, P.A. (2006) Role of Phosphate-Solubilizing Microorganisms in Sustainable Agriculture-A Review. Agronomy for Sustainable Development, 27, 29-43. http:/ /dx.doi.org/10.1051/agro:2006011

Kinkle BK, Sadowsky MJ, Johnstone K, Kokinen WC (1994) Tellurium and selenium resistance in rhizobia and its potential use for direct isolation of Rhizobium meliloti from Soil. Appl Environ Microbiol 60:1674-1677 
Kloepper JW, Schroth MN (1981) Relationship of in vitro antibiosis of plant growth promoting rhizobacteria to plant growth and the displacement of root microflora. Phytopathol 71: 1020-1024.

Krasova-Wade T, Diouf O, Ndoye I, Sall CE, Braconnier S, Neyra M (2006) Water condition effects on rhizobia competition for cowpea nodule occupancy. African J Biotech 5:1457-1463

Kumar S, Mukerji KG, Lai R (1996) Molecular aspects of pesticide degradation by microorganisms. Crit Rev Microbiol 22:1-26

Lakzian A, Murphy P, Turner A, Beynon JL, Giller KE (2002) Rhizobium leguminosarum bv. viciae populations in soils with increasing heavy metal contamination: abundance, plasmid profiles, diversity and metal tolerance. Soil Biol Biochem 34:519-529

Lloret J, Wulff BBH, Rubio JM, Downie JA, Bonilla I, Rivilla R (1998) Exo-polysaccharide II production is regulated by salt in the halotolerant strain Rhizobium meliloti EFB1. J Bacteriol 179:5366-5371

Lloret J, Bolanos L, Lucas MM, Peart JM, Brewin NJ, Bonilla I, Rivilla R (1995) Ionic stress and osmotic pressure induce different alterations in the lipopolysaccharide of a Rhizobium meliloti strain. Appl Environ Microbiol 61:3701-3704

Lugtenberg B, Kamilova F (2009) Plant growth promoting rhizobacteria. Ann Rev Microbiol 63:541-556

Lucy M, Reed E, Glick BR (2004) Applications of free living plant growth promoting rhizobacteria. Antonie Van Leeuwenhoek 86:1-25

Ma W, Charles TC, Glick BR. (2004) Expression of an exogenous 1-aminocyclopropane-1-carboxylate deaminase gene in Sinorhizobium meliloti increases its ability tonodulate alfalfa. Appl Environ Microbiol;70:5891-7.

Ma Y, Prasad MNV, Rajkumar M, Freitas H (2011) Plant growth promoting rhizobacteria and endophytes accelerate phytoremediation of metalliferous soils. Biotechnol Adv 29:248-258

Ma Z, Ge L, Lee ASY et al. (2008) Simultaneous analysis of different classes of phytohormones in coconut (Cocos nucifera L.) water using high-performance liquid chromatography and liquid chromatography-tandem mass spectrometry after solid-phase extraction. Anal Chim Acta 610: 274-281.

Mathur SC (1999) Future of Indian pesticides industry in next millennium. Pestic Inf 24:9-23

Martinez-Toledo MV, Salmeron V, Rodelas B, Pozo C, Gonzalez-Lopez J (1996) Studies on the effects of the herbicide simazine on microflora of four agricultural soils. Environ Toxicol Chem 15:1115-1118

Meghvansi, M.K. (2006) Isolation, Identification and Effectiveness of Rhizobial Strains and Arbuscular Mycorrhizal (AM) Fungi of Soybean Cultivars Grown in Bundi and Udaipur, Rajasthan. PhD Thesis, Maharshi Dayanand Saraswati University, Ajmer.

Mehboob I, Naveed M, Zahir ZA, Ashraf M (2012) Potential of rhizobia for sustainable production of non-legumes. In: Ashraf M, O “ ztu“rk M, Ahmad M, Aksoy A (eds) Crop production for agricultural improvement. Springer, Netherlands, pp 659-704

Miller-Williams M, Loewen PC, Oresnik IJ (2006) Isolation of salt sensitive mutants of Sinorhizobium meliloti strain Rm1021. Microbiol 152:2049-2059

Mishra RPN, Singh RK, Jaiswal HK, Kumar V, Maurya S (2006) Rhizobium-mediated induction of phenolics and plant growth promotion in rice (Oryza sativa L.). Curr Microbiol 52:383-389

Mpepereki SF, Makoneses Wollum AG (1997) Physiological characterization of indigenous rhizobia nodulating Vigna unguiculata in Zimbabwean soils. Symbiosis 22:275-292

Muglia CI, Grasso DH, Aguilar OM (2007) Rhizobium tropici response to acidity involves activation of glutathione synthesis. Microbiol 153:1286-1296

Munns DN, Keyser HH, Fogle VW, Hohenberg JS, Righetti TL, Lauter DL, Zaruog MG, Clarkin KL, Whitacre KW (1979) Tolerance of soil acidity in symbiosis of mung bean with rhizobia. Agron J 71:256-260

Nandal K, Sehrawat AR, Yadav AS, Vashishat RK, Boora KS (2005) High temperature-induced changes in exo-polysaccharides, lipopolysaccharides and protein profile of heat-resistant mutants of Rhizobium sp. (Cajanus). Microbiol Res 160:367-373

Naamala J, Jaiswal SK. Dakora FD. (2016) Antibiotics Resistance in Rhizobium: Type, Process, Mechanism and Benefit for Agriculture Curr Microbiol.72:804-816

Nascimento F, Brı'gido C, Alho L, Glick BR, Oliveira S (2012) Enhanced chickpea growth promotion ability of a mesorhizobia expressing an exogenous ACC deaminase gene. Plant Soil 353:221-230

Neubauer U, Furrer G, Kayser A, Schulin R (2000) Siderophores, NTA, and citrate: potential soil amendments to enhance heavy metal mobility in phytoremediation. Int J Phytoremed 2:353-368 
Nieto KF, Frankenberger WT Jr (1991) Influence of adenine, isopentyl alcohol and Azotobacter chroococcum on the vegetative growth of Zea mays. Plant Soil 135:213-221

Nonnoi F, Chinnaswamy A, de la Torre VSG, de la Pe na TC, Lucas MM, Pueyo JJ (2012) Metal tolerance of rhizobial strains isolated from nodules of herbaceous legumes (Medicago spp. and Trifolium spp.) growing in mercury-contaminated soils. Appl Soil Ecol 61:49-59

Oldroyd GED (2013). Signalling systems that promote beneficial symbiotic associations in plants. Nat Rev Microbiol;11:252-63.

Ozkoc I, Deliveli MH (2001) In vitro inhibition of the mycelia growth of some root rot fungi by Rhizobium leguminosarum biovar phaseoli isolates. Turk J Biol 25:435-445

Parker JH (1972) How fertilizer moves and reacts in soil. Crops Soils 72:7-11

Patten CL, Glick BR (1996) Bacterial biosynthesis of indole-3-acetic acid. Can J Microbiol 42:207-220

Paton GI, Palmer G, Burton M, Rattray EAS, McGrath SP, Glover LA, Killham K (1997) Development of an acute and chronic ecotoxicity assay using lux-marked Rhizobium leguminosarum biovar trifolii. Lett Appl Microbiol 24:296-300

Paudyal SP, Aryal RR, Chauhan SVS, Maheshwari DK (2007) Effect of heavy metals on growth of rhizobium strains and symbiotic efficiency of two species of tropical legumes. Sci World 5:27-32

Peoples MB, Crasswell ET (1992) Biological nitrogen fixation: investments, expectations and actual contributions to agriculture. Plant Soil 141:13-39

Peix A, Rivas-Boyero AA, Mateos PF, Rodriguez-Barrueco C, Martı́nez-Molina E, Velazquez E (2001) Growth promotion of chickpea and barley by a phosphate solubilizing strain of Mesorhizobium mediterraneum under growth. Soil Biol Biochem 33:103-110

Pereira SIA, Lima AIG, Figueira EMAP (2006a) Heavy metal toxicity in Rhizobium leguminosarum biovar viciae isolated from soils subjected to different sources of heavy-metal contamination: effects on protein expression. Appl Soil Ecol 33:286-293

Pereira SIA, Lima AIG, Figueira EMAP (2006b) Screening possible mechanisms mediating cadmium resistance in Rhizobium leguminosarum bv. viciae isolated from contaminated Portuguese soils. Microbial Ecol 52:176-186

Plessner, O., Klapatch, T., and Guerinot, M.L. (1993) Siderophore utilization by Bradyrhizobium japonicum. Appl. Environ. Microbiol. 59:1688-1690.

Prabha C, Maheshwari DK, Bajpai VK (2013) Diverse role of fast growing rhizobia in growth promotion and enhancement of psoralen content in Psoralea corylifolia L. Pharmacogn Mag 9:S57-S65

Pulsawat W, Leksawasdi N, Rogers PL, Foster LJR (2003) Anions effects on biosorption of Mn(II) by extracellular polymeric substance (EPS) from Rhizobium etli. Biotechnol Lett 25:1267-1270

Rajendran G, Sing F, Desai AJ, Archana G (2008) Enhanced growth and nodulation of pigeonpea by co-inoculation of Bacillus strains with Rhizobium sp. Bioresour Technol 99:544-550

Rajkumar M, Ae N, Prasad MNV, Freitas H (2010) Potential of siderophore-producing bacteria for improving heavy metal phytoextraction. Trends Biotechnol 28:142-149.

Reigh, G. and O'Connell, M. (1993) Siderophore iron transport correlates with the presence of specific ironregulated proteins in the outer membrane of Rhizobium meliloti. J. Bacteriol. 175:94-102.

Reitz M, Rudolph K, Schroder I, Hoffmann-Hergarten S, Hallmann J, Sikora RA (2000) Lipopolysaccharides of Rhizobium etli strain G12 act in potato roots as an inducing agent of systemic resistance to infection by the cyst nematode Globodera pallida. Appl Environ Microbiol 66:3515-3518

Remans R, Ramaekers L, Schelkens S, Hernandez G, Garcia A, Reyes JL, Mendez N, Toscano V, Mulling M, Galvez L, Vanderleyden J (2008) Effect of Rhizobium-Azospirillum coinoculation on nitrogen fixation and yield of two contrasting Phaseolus vulgaris L. genotypes cultivated across different environments in Cuba. Plant Soil 312:25-37

Richardson AE, Henderson AP, James GS, Simpson RJ (1988) Consequences of soil acidity and the effect of lime on the nodulation of Trifolium subterraneum L. growing in an acid soil. Soil Biol Biochem 20:439-445

Saxena D, Amin M, Khanna S (1996) Modulation of protein profiles in Rhizobium sp. under salt stress. Can J Microbiol 42:617-620

Schippers, B., Bakker, A.W., Van peer, R. (1990) Beneficial and deleterious pseudomonads on rhizosphere interactions.Plant Soil, 129, 75-83. 
Senthilkumar M, Madhaiyan M, Sundaram SP, Kannaiyan S (2009) Intercellular colonization and growth promoting effects of Methylobacterium sp. with plant-growth regulators on rice (Oryza sativa L. CvCO-43). Microbiol Res 164:92-104

Sharma P, Padh H, Shrivastava N (2013) Hairy root cultures: a suitable biological system for studying secondary metabolic pathways in plants. Eng Life Sci 13:62-75

Singh, Y., Ramteke, P.W. and Shukla, P.K., (2013) Characterization of Rhizobium isolates of pigeon pea rhizosphere from Allahabad soils and their potential pgpr characteristics. International Journal of Research in Pure and Applied Microbiology, 3(1), 4-7.

Spaepen S, Vanderleyden J (2011) Auxin and plant-microbe interactions. Cold Spring Harb Perspect Biol 3:a001438

Stan V, Gament E, Cornea CP, Voaides C, Dusa M, Plopeanu G (2011) Effects of heavy metal from polluted soils on the Rhizobium diversity. Not Bot Hort Agrobot Cluj 39:88-95

Subbarao GV, Johansen C, Jana MK, Kumar Rao JVDK (1990) Effects of the sodium/calcium ratio in modifying salinity responses in pigeonpea (Cajanus cajan). Plant Physiol 136:439-443

Subbarao GV, Sahrawat KL, Nakahara K, Ishikawa T, Kishii M, Rao IM, Hash CT, George TS, Srinivasa Rao P, Nardi P, Bonnett D, Berry W, Suenaga K, Lata JC (2012) Bio-logical nitrification inhibition-a novel strategy to regulate nitrification in agricultural systems. Adv Agron 114:249-302

Sutherland IW (2001) Exo-polysaccharides in biofilms, flocs and related structure. Water Sci Technol 43:77-86

Tao G, Tian S, Cai M, Xie G (2008) Phosphate solubilizing and mineralizing abilities of bacteria isolated from soils. Pedosphere 18:515-523

Tchebotar VK, Kang UG, Asis CA Jr, Akao S (1998) The use of GUS-reporter gene to study the effect of Azospirillum-Rhizobium co-inoculation on nodulation of white clover. Biol Fertil Soils 27:349-352

Thami-Alami I, Elboutahiri N, Udupa SM (2010) Variability in natural populations of Sinorhizobium meliloti in Morocco. In: Porqueddu C, Ríos S (eds) The contributions of grasslands to the conservation of Mediterranean biodiversity. Zaragoza, CIHEAM/ CIBIO/FAO/SEEP, pp 265-269

Tokala RK, Strap JL, Jung CM, Crawford DF, Salove MH, Deobald LA, Bailey JF, Morra MJ (2002) Novel plant-microbe rhizosphere interaction involving Streptomyces lydicus Wyec 108 and the pea plant (Pisum sativum). Appl Environ Microbiol 68:2161-2171

Uren NC (2007) .Types, amounts, and possible functions of compounds released into the rhizosphere by soil-grown plants. In: Pinton R, Varanini Z, Nannipieri P (eds) The rhizosphere: biochemistry and organic substances at the soil-plant interface. CRC Press, Boca Rato'n, pp 1-22

Verma JP, Yadav J, Tiwari KN, Kumar A (2013) Effect of indigenous Mesorhizobium spp. and plant growth promoting Rhizobacteria on yields and nutrients uptake of chickpea (Cicer arietinum L.) under sustainable agriculture. Ecol Eng 51:282-286

Verma JP, Yadav J, Tiwari KN, Jaiswal DK (2014) Evaluation of plant growth promoting activities of microbial strains and their effect on growth and yield of chickpea (Cicer arietinum L.) in India. Soil Biol Biochem 70:33-37

Vessey KJ (2003) Plant growth promoting rhizobacteria as biofertilizers. Plant Soil 255:571-586

Villacieros M, Power B, Sanchez-Contreras M, Lloret J, Oruezabal RI, Martin M, Fernandez-Pinas F, Bonilla I, Whelan C, Dowling DN, Rivilla R (2003) Colonization behaviour of Pseudomonas fluorescens and Sinorhizobium meliloti in the alfalfa (Medicago sativa) rhizosphere. Plant Soil 251:47-54

Walton DC, Li Y (1995) Abscisic acid biosynthesis and metabolism. Plant hormones: physiology, biochemistry and molecular biology. Kluwer, Dordrecht, pp 140-157

Watkin ELJ, O'Hara GW, Glenn AR (1997) Calcium and acid stress interact to affect the growth of Rhizobium leguminosarum bv. trifolii. Soil Biol Biochem 29:1427-1432

Watkin ELJ, O'Hara GW, Glenn AR (2003) Physiological responses to acid stress of an acid-soil tolerant and an acid-soil sensitive strain of Rhizobium leguminosarum biovar trifolii. Soil Biol Biochem 35:621-624

Whipps JM (2001). Microbial interactions and biocontrol in the rhizosphere. J. Experiment. Bot., 52: 487-511.

Wilson PW, Burris RH (1947). The mechanism of biological nitrogen fixation. Bacteriol Rev 11(1):41-73

Wright GD (2007) The antibiotic resistome: the nexus of chemical and genetic diversity. Nat Rev Microbiol 5:175-186

Xavier G, Martins L, Neves M, Rumjanek N (1998) Edaphic factors as determinants for the distribution of intrinsic antibiotic resistance in a cowpea rhizobia population. Biol Fertil Soils 27:386-392.

Yelton MM, Yang SS, Edie SA, Lim ST (1983) Characterization of an effective salt-tolerant fast-growing strain of Rhizobium japonicum. J Gen Microbiol 129:1537-1547 
Zahran HH (1999) Rhizobium-legume symbiosis and nitrogen fixation under severe conditions and in an aird climate. Microbiol Mol Biol Rev 63(4):968-989

Zafar-ul-Hye M, Ahmad M, Shahzad SM (2013) Synergistic effect of rhizobia and plant growth promoting rhizobacteria on the growth and nodulation of lentil seedlings under axenic conditions. Soil Environ 32:79-86

Zaidi A, Khan MS, Ahemad M and Oves M, (2009) Plant growth promotion by phosphate solubilizing bacteria. Acta Microbiol Immunol Hung 56:263-284.

Zhan HJ, Lee CC, Leigh JA (1991) Induction of the second exopolysaccharide (EPS) in Rhizobium meliloti SU47 by low phosphate concentrations. J Bacteriol 173:7391-7394

Zhang XP, Karsisto M, Harper R, LindstroE`m K (1991) Diversity of Rhizobium bacteria isolated from the root nodules of leguminous trees. Int J Syst Evol Bacteriol 41:104-113 